\title{
Estimation of Reverberation Time in Classrooms Using the Residual Minimization Method
}

\author{
Artur NOWOŚWIAT, Marcelina OLECHOWSKA
}

\author{
Faculty of Civil Engineering
}

Silesian University of Technology

Akademicka 5, 44-100 Gliwice, Poland; e-mail: \{artur.nowoswiat, marcelina.olechowska\}@polsl.pl

(received March 30, 2017; accepted June 27, 2017)

\begin{abstract}
The objective of the residual minimization method is to determine a coefficient correcting the Sabine's model. The Sabine's equation is the most commonly applied formula in the designing process of room acoustics with the use of analytical methods. The correction of this model is indispensable for its application in rooms having non-diffusive acoustic field. The authors of the present paper will be using the residual minimization method to work out a suitable correction to be applied for classrooms. For this purpose, five different poorly dampened classrooms were selected, in which the measurements of reverberation time were carried out, and for which reverberation time was calculated with the use of theoretical methods. Three of the selected classrooms had the cubic volume of $258.5 \mathrm{~m}^{3}$ and the remaining two had the cubic volume of $190.8 \mathrm{~m}^{3}$. It was sufficient to estimate the correction for the Sabine's equation. To verify the results, three other classrooms were selected, in which also the measurements of reverberation time were carried out. The results were verified by means of real measurements of reverberation time and by means of computer simulations in the program ODEON.
\end{abstract}

Keywords: reverberation time; Sabine's formula; classroom; Residual Minimization Method; coefficient correcting the Sabine's model; ODEON.

\section{Introduction}

We have plenty of research works (LEE, ChAnG, 1999; Twardella et al., 2012; Kielb et al., 2014; Agarwal, Shiva Nagendra, 2016) which describe the microclimate of the classroom. Among them there are also studies such as (KRÜGER, ZANNIN, 2004) which, apart from the microclimate or heating comfort, also take in hand the acoustic comfort.

In fact, over the last 50 years, as written by CAMPBELL et al. (2014) the awareness involving the significance of acoustics in school classrooms had been continually rising. One of the most important parameters of classroom acoustics is reverberation time. But there are also studies, e.g. (Prodi et al., 2010) in which the authors point out that alongside full intelligibility of speech, which must be ensured for the listener, it is worth while minimizing the effort of the listener to understand the words. The significance of the issue of time reverberation in classrooms had been already described by Bistafa and Bradley (2000), who simulated school classrooms using computer programs, and simulating the parameters of sound absorption they compared the experimental results with the analytical or computer generated results. Before them, there had been other works, e.g. written by HodGson (1999) in which, having investigated several dozen school classrooms, he declared that the reverberation inside them was excessive. Anyway, Bradley was so interested in classroom acoustics that he published another work involving the results of acoustic measurements and speech intelligibility in 12 different schools (BRADLEY, SATO, 2008). The subject of classroom is so important that new works are being provided on this subject. There have been studies (LeŚnA, Skrodzka, 2010) involving the subjective impressions of pupils at different school age. The opinions were being verified by objective measurements of reverberation time. The subjective impressions, but not only the ones involving acoustic parameters, were also investigated in the work (YANG et al., 2013). In that case, apart from acoustic impressions, the authors were investigating the perception of furniture in the classroom, the impact of temperature, the quality of air and artificial lighting. 
The research studies of 110 classrooms in five primary schools in Warsaw (MikuLsKi, RADOsz, 2011) pointed out a large variety of acoustic parameters, i.e. reverberation time and speech transmission index. The studies involved also the impact of pupils in the class on reverberation conditions (CHOI, 2016), and it was found that the said impact depended on the reverberation properties of the empty room.

We can state that the comfort of people staying in a room is conditioned by the lack of noise. FronTCZAK et al. (2012) demonstrated that the investigated people pointed out to sound privacy as one of the major factors contributing to the discomfort of staying in a room.

The problem of excessive sound reverberation in classrooms is common worldwide, which was confirmed by the research studies (MEALINGS et al., 2015). Very interesting research studies on the relation of the signal to noise and to reverberation time were carried out and addressed to warm tropical climate (JoHN et al., 2016) and in such a climate $\mathrm{RT}_{30}$, STI (DONGRE et al., 2017). Another approach to classroom designing involves the application of multi-criteria methods, e.g. AHP to improve the intelligibility of speech. Such an approach was applied by Madbouly and his team (MAODBouly et al., 2016), who, for the problem of learning efficiency, applied for the AHP method the analysis of five criteria of acoustic characteristics. Reverberation time plays an important role in understanding speech in rooms (Nowoświat, Olechowska, 2016a) and also in classrooms. There are many research studies which focus on STI, and most of them involve office rooms (Hongisto, 2005; HAKA et al., 2009; LeE, JEON, 2014).

Many of the described above works involve measurements, and only a few are focused on theoretical models. It is worth noting that theoretical models based on the theory of statistics are burdened with big errors. There are many works which verify theoretical models, using measurement or computer simulations, e.g. (Kang, Neubauer, 2001). The estimation error of reverberation time with the use of analytical methods is greatly dependent on the proper determination of sound absorption coefficients of room envelopes. The problem had been addressed by BERANEK (2006). Having investigated relevant examples, he declared that the Sabine's equation could be used to determine reverberation time in a room for which the coefficient $\alpha$ had been earlier determined in a similar place. The review of all theoretical models and research studies which test or verify these models can be found in the paper of Nowoświat (Nowoświat, Olechowska, 2016b).

The distribution of noise is not limited to classrooms. Interesting research studies involving the discussed problem have been also carried out in sacral rooms (BERARDI et al., 2009). The prediction of sound distribution in rooms and following it prediction of acoustic parameters can be realized by means of computer simulations (BERARDI, 2014). In such cases it is very important to select appropriate sound absorption coefficients limiting the room.

Taking into consideration all aspects mentioned above, and in particular the error resulting from the selection of material parameters or the lack of diffusivity of the acoustic field, the authors of the present paper have undertaken a task to work out a method which adds extra value to the Sabine's model. Such a revaluation can be done by the residual minimization method MMR (Nowoświat et al., 2016). The correction coefficient of Sabine's model determined with the use of MMR method can be determined for a definite type of room. In this paper the authors present in detail a way to estimate reverberation time using the MMR method. By choosing such an approach, we wanted to ensure a comprehensive explanation of the procedural algorithm. Therefore, some points of the algorithm were presented as in the paper (Nowoświat et al., 2016). However, in this paper the algorithm was applied for the classroom.

\section{Methodology}

\subsection{Residual Minimization Method}

Developing the statement of BerAneK (2006), which reads that the Sabine's equation can be used for rooms similar to the rooms for which sound absorption coefficient has been already determined, we can apply the described MMR method (Nowoświat et al., 2016). But our approach goes one step further and makes it possible to determine the correction of Sabine's equation, allowing not only for sound absorption coefficient of similar rooms, but also for their geometry, cubic volume or the diffusion of acoustic field. In the MMR method, we select $n$ rooms of similar geometry, similar average sound absorption coefficient, similar sound dispersion and similar cubic volumes within predetermined range of $\left\langle V_{\min }, V_{\max }\right\rangle$. For this paper it is a classroom. For each of the rooms, we calculate reverberation times, using the following formulas: (1) Sabine's $\left(T_{\mathrm{Sab}}\right),(2)$ Eyring's $\left(T_{\mathrm{Eyr}}\right)$, (3) Millington's ( $\left.T_{\text {Mil }}\right)$, (4) Kuttruff's $\left(T_{\text {Kut }}\right)$, (5) Fitzroy's $\left(T_{\mathrm{Fit}}\right)$, (6) Arau-Puchades' ( $\left.T_{\text {Arau }}\right),(7)$ Neubauer's $\left(T_{\text {Neub }}\right)$, (8) Pujolle's $\left(T_{\text {Puj }}\right),(9)$ Cremer's $\left(T_{\text {Cre }}\right)$, (Cremer, MülLER, 1982), (10) Standard EN ( $\left.T_{\mathrm{EN}}\right)$ (EN 12354$6,2003)$ as well as a very interesting formula (11) $r_{\mathrm{HND}}$ (Arau-Puchades, Berardi, 2013). Then, the minimum difference is determined from among the differences $R_{1}=T_{p}-T_{\mathrm{Sab}}, R_{2}=T_{p}-T_{\mathrm{Eyr}}, \ldots, R_{10}=$ $T_{p}-T_{\mathrm{ISO}}, R_{11}=T_{p}-T_{r_{\mathrm{HND}}}$ (referred to as residues), where $T_{p}$ - measured reverberation time.

The definitions of reverberation time $T$ and those of correction functions $K$ are accepted as provided in the work (Nowoświat et al., 2016) as the functions of 
the domain of $F=\{125,250,500,1000,2000,4000\}$ and the set of values $\mathbb{R}_{+}$, where to each arbitrary point $f \in F$ the point $T(f) \in \mathbb{R}_{+}$for the reverberation time and $K(f) \in \mathbb{R}_{+}$for the correction function are assigned respectively. The correction function $K$ is determined in a few steps, as follows:

1) We calculate reverberation time for each frequency $f_{k}$, using all methods (1)-(10), and then we calculate the residues $R_{1}, R_{2}, \ldots, R_{10}$. If the residues are of the same signs, we determine $R_{\text {min }}=\min \left\{\left|R_{1}\right|,\left|R_{2}\right|, \ldots,\left|R_{n}\right|\right\}$ and then we select the reverberation time $T\left(f_{k}\right)$ calculated with the formula which corresponds to the residue $R_{\text {min }}$. But if the residues are of different signs, then $T\left(f_{k}\right)=\frac{T_{\text {theoretical }, A}\left(f_{k}\right)+T_{\text {theoretical }, B}\left(f_{k}\right)}{2}$ where $T_{\text {theoretical, } A}\left(f_{k}\right)$ corresponds to the reverberation time calculated with the formula which corresponds to the lowest residue of all the positive residues, and $T_{\text {theoretical, } B}\left(f_{k}\right)$ corresponds to the reverberation time calculated with the formula which corresponds to the highest residue of all the negative residues. In this way, we obtain the points $\left(f_{k}, T\left(f_{k}\right)\right)$ which we approximate with the use of the least squares method, which yields the polynomial $T_{t}(f)$.

2) We determine the points $K$, using the following rule:

$$
\begin{aligned}
K_{125} & =\frac{T_{t}(125)}{T_{\mathrm{av}, \mathrm{Sab}}(125)}, & K_{250} & =\frac{T_{t}(250)}{T_{\mathrm{av}, \mathrm{Sab}}(250)}, \\
K_{500} & =\frac{T_{t}(500)}{T_{\mathrm{av}, \mathrm{Sab}}(500)}, & K_{1000} & =\frac{T_{t}(1000)}{T_{\mathrm{av}, \mathrm{Sab}}(1000)}, \\
K_{2000} & =\frac{T_{t}(2000)}{T_{\mathrm{av}, \mathrm{Sab}}(2000)}, & K_{4000} & =\frac{T_{t}(4000)}{T_{\mathrm{av}, \mathrm{Sab}}(4000)},
\end{aligned}
$$

where $T_{\mathrm{av}, \mathrm{Sab}}\left(f_{k}\right)$ is the average Sabine's reverberation time, for the frequency $f_{k}$ determined from all rooms.

3) Using the least squares method, we determine the corrective function $K(f)$. The obtained function is a polynomial approximating the points specified in point 2 .

4) We determine, as a frequency function, the corrected Sabine's reverberation time described by the following equation

$$
T_{\text {Sabine_sk }}(f)=K(f) \cdot T_{\text {sab }}(f),
$$

where $T_{\text {Sabine_sk }}(f)$ - adjusted Sabine's reverberation time as a frequency function, $T_{\text {sab }}(f)-$ Sabine's reverberation time as a frequency function, $K(f)$ - corrective function determined in point 3 .

\subsection{Measurement}

The measurements were carried out in 5 classrooms and next in the 3 classrooms. The dimensions of the classrooms were different. The classrooms marked as classroom_334, classroom_335, classroom_336, classroom_337 had the length of $12.6 \pm 0.1 \mathrm{~m}$ and the width of $6.7 \pm 0.1 \mathrm{~m}$. And the classrooms marked as classroom_325, classroom_327, classroom_329, clasroom_337A had the length of $9.4 \pm 0.1 \mathrm{~m}$ and the width of $6.7 \pm 0.1 \mathrm{~m}$. The sound absorption coefficients of the envelopes limiting the room were accepted as in Ta-

\begin{tabular}{|c|c|c|c|c|c|c|}
\hline \multirow{3}{*}{ Material } & \multicolumn{6}{|c|}{ Sound absorption coefficient } \\
\hline & \multicolumn{6}{|c|}{ Frequency bands } \\
\hline & 125 & 250 & 500 & 1000 & 2000 & 4000 \\
\hline Plaster on concrete & 0.02 & 0.02 & 0.03 & 0.04 & 0.05 & 0.05 \\
\hline PCV on concrete & 0.02 & 0.02 & 0.03 & 0.04 & 0.04 & 0.05 \\
\hline Windows & 0.35 & 0.25 & 0.18 & 0.12 & 0.07 & 0.04 \\
\hline
\end{tabular}
ble 1 .

Table 1. Sound absorption coefficients of the materials present in the investigated school classrooms.

The measurement was carried out with the use of the apparatus which consisted of the transmission part and the reception part. The transmission part comprised the following elements:

- a column loudspeaker of spherical radiation characteristic,

- a pink and white noise generator together with an amplifier.

The reception part of the setup consisted of the following elements:

- an acoustic analyzer,

- a microphone,

- a preamplifier,

- an acoustic calibrator,

- a PC computer with software.

The measurements were carried out in an empty room, i.e. without furniture. The measurements of reverberation time were carried out, using the interrupted noise method. The interior was being excited by means of a broadband noise shaped in such a way as to ensure approximately pink spectrum of steady-state reverberant sound for the range comprising $1 / 3$ octave bands of the middle frequencies of $50-5000 \mathrm{~Hz}$. The sound source was generating the level of acoustic pressure sufficient to ensure that the decay curve started at least $35 \mathrm{~dB}$ above the acoustic background within the respective frequency range. In each investigated room (Fig. 1), 6 measurement points were located.

The measurements were carried out for two different locations of the column loudspeaker. In order to 
a)

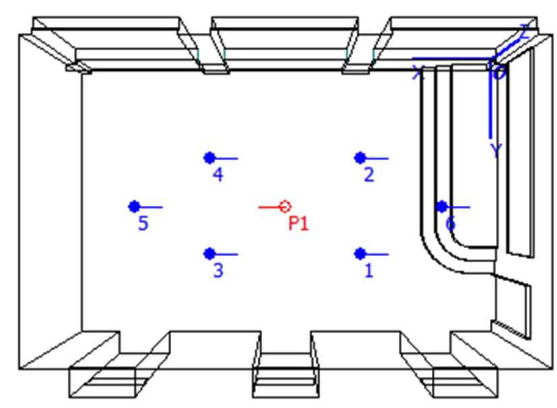

b)

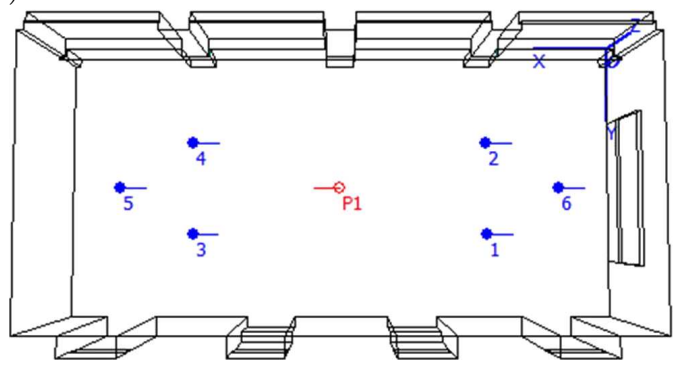

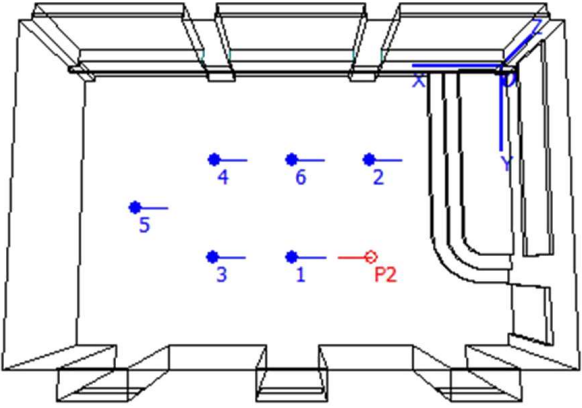

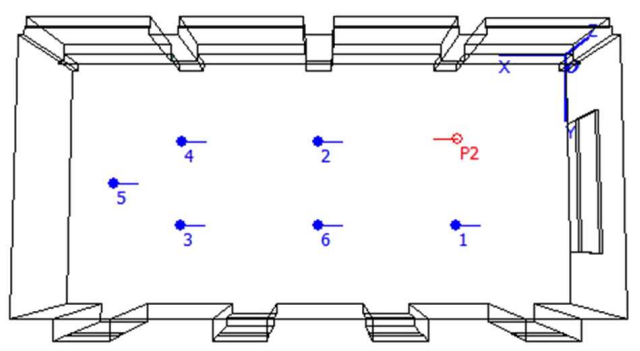

Fig. 1. Two types of classroom: a) smaller, b) larger. The illustrations show two locations of the sound source P1 and P2 and the arrangement of measurement points.

obtain high accuracy results and to minimize the impact of the excitation signal randomness, the measurement was repeated six time at each point. Altogether, in each room, 72 measurements were analyzed. The values of the obtained reverberation times were approximated, using the statistics three sigma rule. The measurement points were placed at the height of $1.2 \mathrm{~m}$ from the floor and at least $1 \mathrm{~m}$ from wall surfaces, and the omni-directional sound source was placed at the height of $1.5 \mathrm{~m}$. Two positions of the sound source P1 and P2 were accepted. The measurement of reverberation time in all the investigated rooms was carried out in accordance with the precision method described in the Standard (ISO 3382-2, 2008). Figure 2 presents the classroom during the measurements.

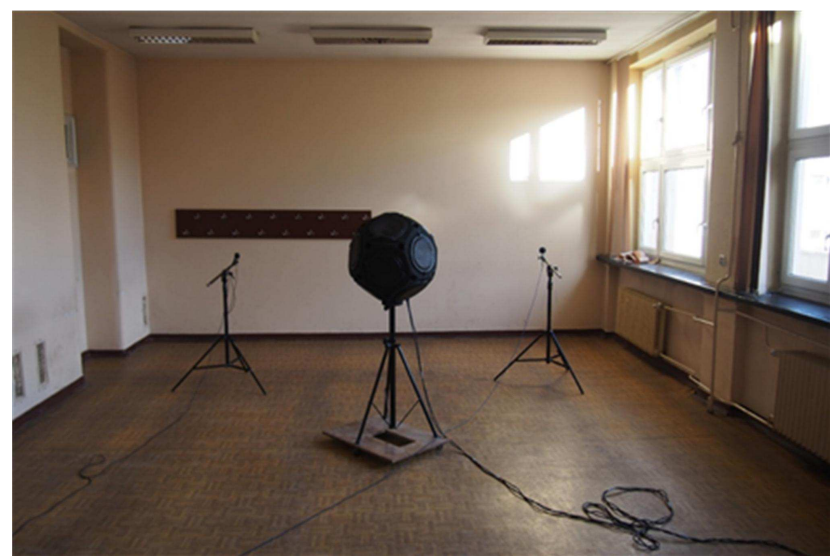

Fig. 2. View of the classroom during the measurement with an exemplary location of a omnidirectional loudspeaker and two measurement points.

\subsection{ODEON simulations}

The computer simulations were carried out using the software ODEON, Version 11.0. As written by PAssero (PAssero, ZANnin, 2010): This software uses the hybrid method, which calculates the early reflections using a combination of the image source method and ray tracing, while the late reflections are calculated by a special ray tracing process generating diffuse secondary sources. The computer simulations were carried out to reflect real classrooms. The acoustic parameters of the envelopes were accepted in congruence with the list of materials enclosed in ODEON. The dissipation coefficients of 0.1 were applied for most of the surfaces limiting the room. A similar approach was applied by AsTOLFI et al. (2008) in his classroom simulations. Furthermore, the sound source and measurement points were located at the same points as the real measurement.

\section{Results}

The research studies involved 8 rooms, including 5 rooms of the cubic volume of $258.5 \pm 0.3 \mathrm{~m}^{3}$ and 3 rooms of the cubic volume of $190.8 \pm 0.3 \mathrm{~m}^{3}$. The rooms were divided into two groups. The first group comprised 3 larger rooms and 2 smaller ones, and the second group consisted of 2 smaller rooms and 1 larger room. The first group, for which the measurement results of reverberation time are presented in Fig. 3a, was applied to determine the coefficient correcting the Sabine's equation, using the MMR method. The sec- 
a)

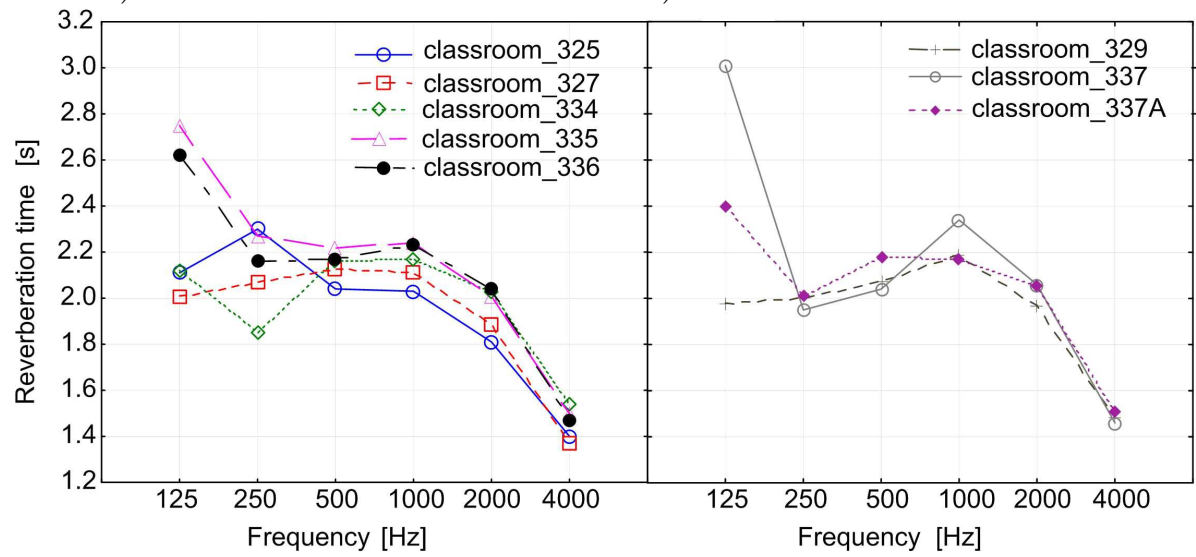

Fig. 3. Measured reverberation times. a) The results of the first group comprising smaller classrooms 325,327 and larger ones 334, 335, 336. b) The results of the second group comprising the larger room 337 and two smaller ones 329, 337A.

ond group, for which the measurement results of reverberation time are presented in Fig. 3b, was applied for verifying the MMR model and for learning algorithm.

For the calculations with the use of the theoretical formulae the following was accepted: the walls and ceiling plastered on the concrete base, PCV placed on the concrete floor, windows of the sound absorption index as presented in Table 1.

We move on to the MMR algorithm. We calculate the differences between the measurement and the theoretical formulas for each of the five classrooms, first of all for the frequency of $125 \mathrm{~Hz}$. It turned out that for the classrooms 325, 327, 334, 336 all the differences were of the same sign (negative) and $R_{\min }=$ $\min \left\{\left|R_{1}\right|,\left|R_{2}\right|, \ldots,\left|R_{n}\right|\right\}=\left|T_{p}-T_{\text {Cre }}\right|$. Therefore, for further calculations we take the reverberation times calculated with the use of Cremer's formula, and we obtain respectively:

$$
\begin{aligned}
& \text { classroom_325 } \Rightarrow T(125)=2.57 \mathrm{~s}, \\
& \text { classroom_327 } \Rightarrow T(125)=2.58 \mathrm{~s}, \\
& \text { classroom_334 } \Rightarrow T(125)=2.60 \mathrm{~s}, \\
& \text { classroom_336 } \Rightarrow T(125)=2.72 \mathrm{~s} .
\end{aligned}
$$

And for the classroom_335 the differences have different signs and $T_{\text {theoretical, } A}(125)=T_{\text {Mill }}=2.74 \mathrm{~s}$, $T_{\text {theoretical }, B}\left(f_{k}\right)=T_{\text {Kut }}=2.76 \mathrm{~s}$ and hence $T(125)=$ $\frac{2.74+2.76}{2}=2.75 \mathrm{~s}$.

Calculating the average value for all $T(125)$, we obtain: $T(125)=2.64 \mathrm{~s}$.

Following the approach, we obtain respectively: $T(250)=3.28 \mathrm{~s}, T(500)=3.10 \mathrm{~s}$.

For the frequencies $1000 \mathrm{~Hz}, 2000 \mathrm{~Hz}$ and $4000 \mathrm{~Hz}$ the formula worked out by Arau-Puchades and Berardi known as $r_{\text {HND }}$ turned out to have the best approximation.

$$
\begin{gathered}
T(1000)=2.72 \mathrm{~s}, \quad T(2000)=2.41 \mathrm{~s}, \\
T(4000)=2.70 \mathrm{~s} .
\end{gathered}
$$

In the following stage we pass the 5th degree approximation polynomial through the points $T(125)$, $T(250), \ldots, T(4000)$ :

$$
\begin{aligned}
T_{t}(x)= & 0.0029 x^{5}-0.0564 x^{4}+0.4728 x^{3}-2.0951 x^{2} \\
& +4.3643 x-0.0444
\end{aligned}
$$

and then we calculate $T_{t}(125)=2.64, T_{t}(250)=3.28$, $T_{t}(500)=3.09, T_{t}(1000)=2.68, T_{t}(2000)=2.31$, $T_{t}(4000)=2.30$.

Next, we calculate the average Sabine's reverberation time for all five classrooms and then $K$, which yields:

$$
\begin{aligned}
K_{125} & =\frac{T_{t}(125)}{T_{\mathrm{av}, \mathrm{Sab}}(125)}=0.91, \\
K_{250} & =\frac{T_{t}(250)}{\mathrm{T}_{\mathrm{av}, \mathrm{Sab}}(250)}=0.92, \\
K_{500} & =\frac{T_{t}(500)}{T_{\mathrm{av}, \mathrm{Sab}}(500)}=0.92, \\
K_{1000} & =\frac{T_{t}(1000)}{\mathrm{T}_{\mathrm{av}, \mathrm{Sab}}(1000)}=0.86, \\
K_{2000} & =\frac{T_{t}(2000)}{T_{\mathrm{av}, \mathrm{Sab}}(2000)}=0.78, \\
K_{4000} & =\frac{T_{t}(4000)}{\mathrm{T}_{\mathrm{av}, \mathrm{Sab}}(4000)}=0.77 .
\end{aligned}
$$

Through the points obtained in this way we pass the approximation polynomial:

$$
\begin{aligned}
y= & 0.0003 x^{5}-0.0023 x^{4}-0.0039 x^{3}+0.0469 x^{2} \\
& -0.0787 x+0.949
\end{aligned}
$$

In this way we obtain: $K(125)=0.9113, K(250)=$ $0.9208, K(500)=0.9163, K(1000)=0.8534$, $K(2000)=0.7405, K(4000)=0.6748$. 
The $K(f)$ determined in this way is applied in the Sabine's equation, which gives:

$$
T_{\text {Sabine_sk }}(f)=K(f) \cdot T_{\text {sab }}(f) \text {. }
$$

Figure 4 presents the results for classroom_329, classroom_337 and classroom_337A. These are classrooms which did not take part in the MMR algorithm.
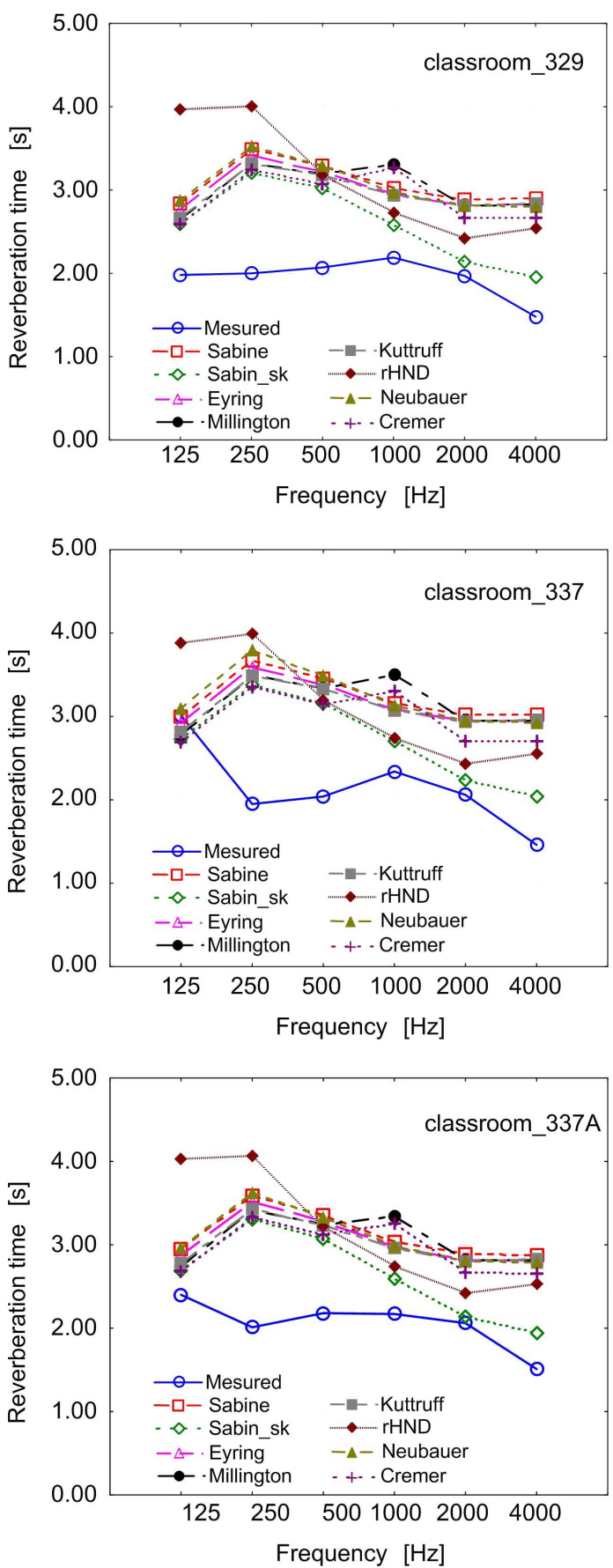

Fig. 4. Results of reverberation time obtained with the use of the measurement, the known theoretical formulas and $T_{\text {Sabine_sk }}$.

\section{Discussion of results}

On the graphs presented in Fig. 4, we are not presenting the results obtained with the use of Fritzroy's, Arau's and Pujol's methods. The reverberation times obtained with the use of those three formulas significantly diverged from the other formulas and from the measurement. Such a situation is not uncommon. Such an effect was already presented by BistafA and BRADLEY (2000) in their work. The differences between calculation results when using different formulas were demonstrated also by Neubauer (Neubauer, Kostek, 2001). The results presented in this paper confirm many other works demonstrating differences between theoretical formulas, as for example the latest research work of (ARAU-PUCHADES, BERARDI, 2015). Therefore, the MMR method was proposed.

The proposed MMR method is basically correcting the Sabine's formula for all rectangular rooms for which the cubic volume $V \in\langle 190.8 ; 258.5\rangle$, the reverberation conditions are as presented in Table 1 and the room geometry is as presented in Fig. 1.

For low frequencies, the results presented in Fig. 4 may give impression of a rather small correction and poor estimation of reverberation time, using the MMR method as compared to the measurement results. It should, however, be noted that the MMR method is not correcting all imperfections of theoretical models. With this method, we can correct the imperfections of the Sabine or Eyring models resulting from the lack of a uniform distribution of acoustic field or from different sound absorption of various envelopes limiting the room. What still remains is the inaccuracy involving inadequately selected or very poorly estimated sound absorption coefficients of the materials limiting the room. The latter inaccuracy has very strong influence on the accuracy of MMR method. However, in spite of this, the method is still considerably improving the results, especially for the frequency of $1000 \mathrm{~Hz}$ or higher.

The classrooms presented in Fig. 4 were also modeled in ODEON. Such a model was made in accordance with the description presented in Subsec. 2.3, accepting all reverberation parameters in line with Table 1 . The results involving the measurement, ODEON model and Sabine_sk are presented in Fig. 5 .

As we can observe, by using the Sabine's formula corrected with the MMR method, we can obtain results which are closer to the measurements than those obtained through computer simulations.

It is also interesting to note that even for the cubic volume beyond that range, the MMR method is correcting the Sabine's reverberation time. In order to verify our statement, we want to present the results of the measurements carried out by other researchers. As an example we propose the room described in the work of MiJıć and MAŠOwić (2010). The studies involved a rectangular room of the dimensions $8.5 \times 8.3 \times 4.3 \mathrm{~m}$. 


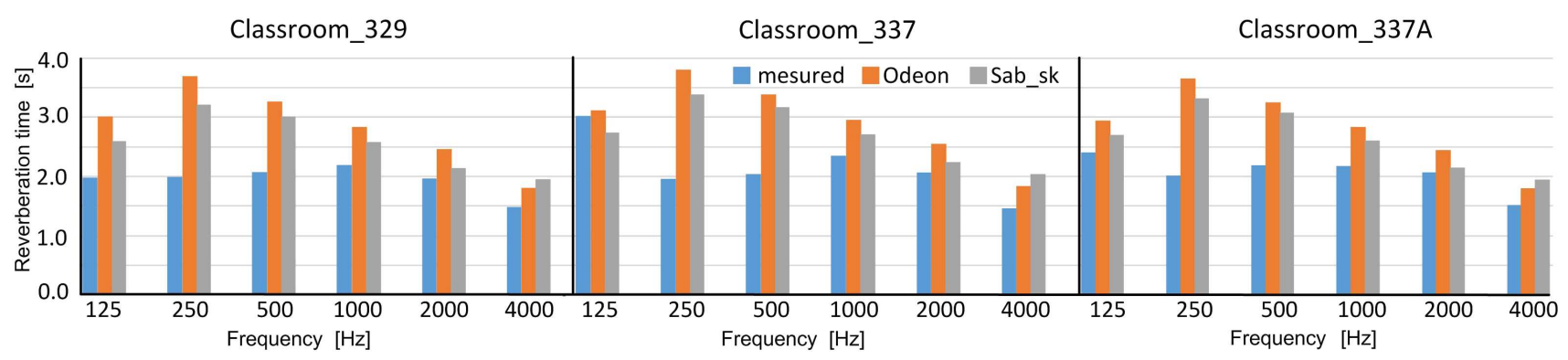

Fig. 5. Reverberation times determined with the use of the measurement, ODEON simulation, Sabine_Sk method, determined by means of MMR.

They accepted the coefficients of sound absorption of the ceiling and walls as for a plastered wall (Table 1), and the floor (Table 2) as for wood parquet flooring.

Table 2. Sound absorption coefficients of the wooden floor.

\begin{tabular}{|c|c|c|c|c|c|c|}
\hline \multirow{3}{*}{ Material } & \multicolumn{6}{|c|}{ Sound absorption coefficient } \\
\cline { 2 - 7 } & 125 & 250 & 500 & 1000 & 2000 & 4000 \\
\cline { 2 - 7 } & 0.25 & 0.15 & 0.10 & 0.09 & 0.08 & 0.07 \\
\hline Parquet & 0.07 concy bands \\
\hline
\end{tabular}

The authors did not provide any information about windows, so we accepted the wall with windows of the same absorption coefficient as without windows. The authors provided information about chairs with soft seat-backs, but they did not provide information about their sound absorption characteristics, so we ignored them in the calculations. The results are presented in Fig. 6.

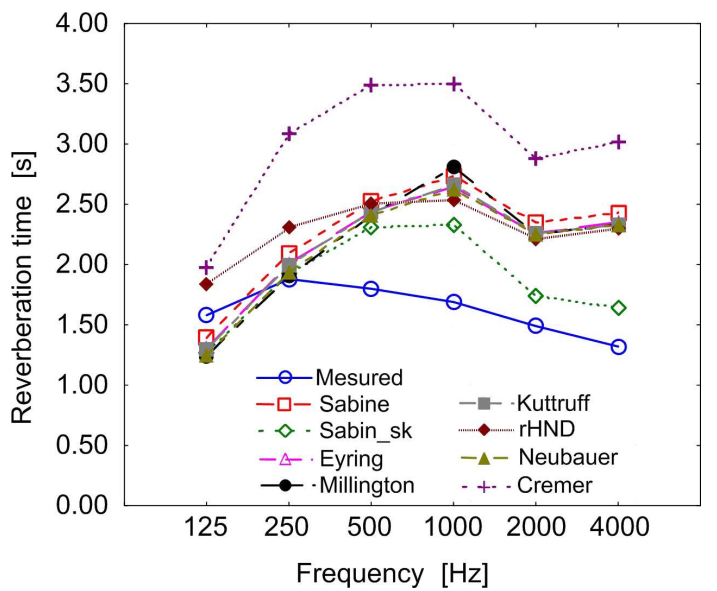

Fig. 6. The results of measurements (MiJić, MAšOvić, 2010) and the results of own calculations yielded by the theoretical formulas and MMR calculations.

Figure 6 very well illustrates that even when we accept quite imprecise sound absorption coefficients, and we apply the MMR correction coefficients for the room which is beyond the calculation range $V$ and which has slightly different geometry, still the correction improves the result of the theoretical formulas. Of course, if we had extended the range of $V$ and included the investigated room and if we had accepted more precise sound absorption coefficients and then determined new correction coefficients using the MMR method, the correction in Fig. 6 would be much more evident.

\section{Conclusions}

The present publication was devoted to the further development and adjustment of the MMR procedure described by the authors (NowoświAT et al., 2016) in their previous work. The adjustment of the procedure consisted in its application for classrooms of the geometry presented in Fig. 1 and sound parameters presented in Table 1. The MMR model was designed to correct the theoretical formulas involving the determination of reverberation time in a room so that it would be possible to estimate the reverberation time for all other similar rooms by means of the corrected Sabine's equation. The model is based, among others, on the measurement of reverberation time in five classrooms which were used to work out the correction of Sabine's formula. The verification of results obtained with the use of the MMR model was done through real measurements in three additional classrooms and through ODEON computer simulations carried out for the same classrooms. Basing on that verification, we can state that the results obtained with the use of the corrected Sabine's model obtained from the MMR algorithm are getting the estimation of reverberation time closer to real measurements, and they are not worse than the computer modeling. As it was already declared, the applied model can be used for classrooms of the cubic volume $V \in\langle 190.8 ; 258.5\rangle$ and the geometry close to that presented in Fig. 1. Since the corrected Sabine's equation has the form of $T=K \cdot \frac{0.161 V}{A}$, the determined in this paper $K$ can be applied for the acoustic adaptation of classrooms. It is important to add that the correction coefficient $K$ can be improved by extending the cubic volume range $V \in\left\langle V_{\min } ; V_{\max }\right\rangle$ with other rooms. Interestingly, even if we apply the determined $K$ for rooms which are beyond the investigated range, but which are, in terms of cubic volume or shape, close 
to the investigated ones, and even if we accept no windows in that room, the results of the corrected Sabine's formula seem to be encouraging (Fig. 6). By applying the proposed MMR algorithm, every researcher can determine for their own objectives the coefficient $K$ correcting the Sabine's formula. Then, they can use it for acoustic adaptation of rooms, or for determining other acoustic parameters of rooms where reverberation is to be considered.

The application scope of this method is limited to rooms big enough to avoid the distortion of measurement results. The size of the room should ensure that the distance between the measurement points is at least one-half sound wavelength (about $2 \mathrm{~m}$ ), the distance of the microphone to the surface limiting the room is at least a quarter wavelength (about $1 \mathrm{~m}$ ) and the minimum distance between the measurement point and the sound source should comply with meet the standards of $\left(d_{\min }=2 \sqrt{\frac{V}{c T}}\right)$. It can be also observed that by ensuring a precise determination of sound absorption of the envelopes limiting the room, we can obtain better convergence of the estimated reverberation time, using the MMR method, with the measurement results. Summing up, we should also outline the advantages and disadvantages of the applied method. On the side of disadvantages we can name the sensitivity involving the selection of the sound absorption coefficient of the envelopes limiting the room. But all theoretical models have similar sensitivity. In the work (Nowoświat et al. 2016), we demonstrate for the tested room built from a homogeneous material (boards with known sound absorption parameters) how well the MMR method is estimating the obtained result. On the side of advantages we can name improved estimation of reverberation time as compared to all theoretical models. Another advantage involves the possibility to estimate the correction coefficient of the Sabine formula. And more importantly, the correction will be different for each room type. The greatest advantage of the method involves the fact that during the designing process of acoustic adaptations we can apply a simple, corrected Sabine's equation, whereby we can obtain the estimation which is more accurate than that obtained with the use of other theoretical equations and comparable to the computer model. Nevertheless, we should be aware that the MMR method is not a new theoretical model, but it is a method based on successive approximations, which applies the known theoretical models.

\section{References}

1. Agarwal N., Shiva Nagendra S.M. (2016), Modelling of particulate matters distribution inside the multilevel urban classrooms in tropical climate for exposure assessment, Building and Environment, 102, 73-82.
2. Arau-Puchades H., Berardi U. (2015), A revised sound energy theory based on a new formula for the reverberation radius in rooms with non-diffuse sound field, Archives of Acoustics, 40, 1, 33-40.

3. Arau-Puchades H., Berardi U. (2013), The reverberation radius in ans enclosure with asymmetrical absorption distribution, Proceedings of Meetings on Acoustics, Vol. 19, ICA 2013 Montreal, Canada, 1-8.

4. Astolfi A., Corrado V., Griginis A. (2008), Comparison between measured and calculated parameters for the acoustical characterization of small classrooms, Applied Acoustics, 69, 966-976.

5. Beranek L.L. (2006), Analysis of Sabine and Eyring equations and their application to concert hall audience and chair absorption, Journal of the Acoustical Society of America, 120, 3, 1399-1410.

6. Berardi U., Cirillo E., Martellotta F. (2009), A comparative analysis of acoustic energy models for churches, Journal of the Acoustical Society of America, 126, 1838.

7. Berardi U. (2014), Simulation of acoustical parameters in rectangular churches, Journal of Building Performance Simulation, 7, 1, 1-16.

8. Bistafa S.R., Bradley J.S. (2000), Predicting reverberation times in a simulated classroom, Journal of the Acoustical Society of America, 108, 1721-1731.

9. Bradley J.S., Sato H. (2008), The intelligibility of speech in elementary school classrooms, Journal of the Acoustical Society of America, 123, 4, 2078-2086.

10. Cambell C., Svensson C., Nilsson E. (2014), The same reverberation time in two identical rooms does not necessarily mean the same levels of speech clarity and sound levels when we look at impact of different ceiling and wall absorbers, INTER-NOISE and NOISE-CON Congress and Conference Proceedings, Vol. 249, no 2, pp. 5446-5461, Australia, 16-19 November.

11. Сноі Y. (2016), Effect of occupancy on acoustical conditions in university classrooms, Applied Acoustics, 114, 36-43.

12. Cremer L., Müller A. (1982), Principles and applications of room acoustics, Vol. 1, p. 235, Applied Science, London.

13. Dongre A.R., Patil A.P., Wahurwagh A.J., Kothari A., Buruchundi K., Manohare M.M. (2017), Acoustical characteristics of classrooms of tropical climate, Applied Acoustics, 121, 46-55.

14. EN 12354-6 (2003), Building acoustics - Estimation of acoustic performance of buildings from the performance of elements - Part 6: Sound absorption in enclosed spaces.

15. Frontczak M., Schiavon S., Goins J., Arens E., ZhANG H., WARGOCKI P. (2012), Quantitative relationships between occupant satisfaction and satisfaction aspects of indoor environmental quality and building design, Indoor Air, 22, 119-131.

16. Haka M., HaApakanges A., KerÄnen J., Hakala J., Keskinen E., Hongisto V. (2009), Perfor- 
mance effects and subjective disturbance of speech in acoustically different office types - a laboratory experiment, Indoor Air, 19, 6, 454-467.

17. Hodgson M. (1999), Experimental investigation of the acoustical characteristics of university classrooms, Journal of the Acoustical Society of America, 106, 4, $1810-1819$.

18. Hongisto V. (2005), A model predicting the effect of speech of varying intelligibility on work performance, Indoor Air, 15, 6, 458-468.

19. ISO 3382-2 (2008), Acoustics - Measurement of room acoustic parameters - Part 2: Reverberation time in ordinary rooms.

20. John J., Thampuran A.L., Premlet B. (2016), Objective and subjective evaluation of acoustic comfort in classrooms: A comparative investigation of vernacular and modern school classroom in Kerala, Applied Acoustics, 104, 33-41.

21. Kang J., Neubauer R.O. (2001), Predicting reverberation time: comparison between analytic formulae and computer simulation, Proceedings of the 17th International Conference on Acoustics (ICA).

22. Kielb C., Lin S., Muscatiello N., Hord W., Rogers-Harrington J., Healy J. (2014), Buildingrelated health symptoms and classroom indoor air quality: a survey of school teachers in New York State, Indoor Air,25, 4, 371-380.

23. Krüger E.L., Zannin P.H.T. (2004), Acoustic, thermal and luminous comfort in classrooms, Building and Environment, 39, 9, 1055-1063.

24. Lee P.J., JeOn J.Y. (2014), A laboratory study for assessing speech privacy in a simulated open-plan office, Indoor Air, 24, 3, 3017-314.

25. Lee S.C., Chang M. (1999), Indoor air quality investigations at five classrooms, Indoor Air, 9, 2, 134-138.

26. LeŚnA P., SkrodzkA E. (2010), Subjective evaluation of classroom acoustics by teenagers vs. reverberation time, Acta Physica Polonica A, 118, 115-117.

27. Madbouly A.I., Noaman A.Y., Ragab A.H.M., Khedra A.M., Fayoumi A.G. (2016), Assessment model of classroom acoustics criteria for enhancing speech intelligibility and learning quality, Applied Acoustics, 114, 147-158.
28. Mealings K.T., Buchholz J.M., Demuth K., DilLON H. (2015), Investigating the acoustics of a sample of open plan and enclosed Kindergarten classrooms in Australia, Applied Acoustics, 100, 95-105.

29. Misıć M., Mašović D. (2010), Reverberation radius in real rooms, Telfor Journal, 2, 2, 86-91.

30. Mikulski W., Radosz J. (2011), Acoustics of classrooms in primary schools - results of the reverberation time and speech transmission index assessments in selected buildings, Archives of Acoustics, 36, 4, 777-793.

31. Neubauer R.O., Kostek B. (2001), Prediction of the reverberation time in rectangular rooms with nonuniformly distributed sound absorption, Archives of Acoustics, 26, 3, 183-201.

32. Nowoświat A., Olechowska M. (2016a), Fast estimation of speech transmission index using the reverberation time, Applied Acoustics, 102, 55-61.

33. Nowoświat A., Olechowska M. (2016b), Investigation studies on the application of reverberation time, Archives of Acoustics, 41, 1, 15-26.

34. Nowoświat A., Olechowska M., Ślusarek J. (2016), Prediction of reverberation time using the residual minimization method, Applied Acoustics, 106, 4250.

35. Passero C.R.M., Zannin P.H.T. (2010), Statistical comparison of reverberation times measured by the integrated impulse response and interrupted noise methods, computationally simulated with ODEON software, and calculated by Sabine, Eyring and Arau-Puchades' formulas, Applied Acoustics, 71, 1204-1210.

36. Prodi C.R.M., Visentin Ch., Farnetani A. (2010), Intelligibility, listening difficulty and listening efficiency in auralized classrooms, Journal of the Acoustical Society of America, 128, 1, 172-181.

37. Twardella D., Matzen W., Lahrz T., Burghardt R., Spegel H., Hendrowarsito L., Frenzel A.C., Fromme H. (2012), Effect of classroom air quality on students' concentration: results of a clusterrendomized crossover experimental study, Indoor Air, 22, 5, 378-387.

38. Yang Z., Becerik-Gerber B., Mino L. (2013), A study on student perceptions of higher education classrooms: Impact of classroom attributes on student satisfaction and performance, Building and Environment, 70, 171-188. 